\title{
Autologous Dendritic Cell-Adenovirus CCL21 Vaccine
}

National Cancer Institute

\section{Source}

National Cancer Institute. Autologous Dendritic Cell-Adenovirus CCL21 Vaccine. NCI

Thesaurus. Code C74015.

A cancer vaccine comprised of autologous dendritic cells (DCs) that have been transduced ex vivo with an adenoviral vector containing the CCL21 gene with potential immunostimulatory and antineoplastic activities. Upon intratumoral administration, autologous dendritic cell-adenovirus CCL21 vaccine expresses the chemokine CCL21, which may induce an antitumoral cytotoxic immune response in the tumor microenvironment. CCL21 [chemokine (C-C motif) lig and 21] has been shown to attract antigen presenting cells (APCs), like leukocytes and DCs, and natural killer (NK) cells and their T-cell effectors to induce a cytotoxic immune response. 